\title{
Von der Besteigung des Steifenjochs
}

Daniel Schlossberg

Korrespondenz:

Dr. med. Daniel Schlossberg

Bachmattstrasse 53

CH-8048 Zürich

daniel.schlossberg@hin.ch
Levi Tramonte suchte sein Domizil an der Via Gracialis auf und beschloss, die Besteigung des Steifenjochs in Angriff zu nehmen.

Er nahm seine Checkliste hervor und las sich vor, was er einzupacken hatte: Unterwäsche, Duschgel, Shampoo, Lektüre, Kaugummi, Traubenzucker, Sackmesser, Medikamente, Ersatzhose und Hemd. Auch ein Pullover durfte nicht fehlen, vom Regenschutz ganz zu schweigen. Die Kreditkarte und das Portemonnaie steckte er in die Innentasche seines Kittels. Ihm fiel auf, dass er noch ein Rezept benötigte, und vereinbarte einen Termin beim Arzt. Seit vielen Jahren ging er an der Via Heretica ein und aus und dachte manchmal im Stillen: Ob da nicht ein p verloren gegangen sei und angesichts der Kundschaft des Doktors sie nicht Via Herpetica heissen müsste? Doch Levi Tramonte war ja selbst auch nicht über alle Zweifel erhaben, und so sprach er beim Doktor vor. Der verstand das Anliegen und stand nun vor der schwierigen Aufgabe, welches Präparat er verschreiben sollte. Levitra konnte bei Levi Tramonte schon lange nichts mehr ausrichten. Die Mitkonkurrenten waren keinen Deut besser, und schliesslich kehrte er mit Mus(s)e an die Via Gracialis zurück. Zuhause angelangt, überlegte er angestrengt, um nicht zu sagen krampfhaft, ob das richtige Mass, das es zu meistern galt, der Steigungsgrad, Öchslegrad oder Härtegrad sei. Die Besteigung des Steifenjochs aber verschob der mittlerweile 90 Lenze zählende Mitstreiter bei vielen Erstbesteigungen auf ein andermal. Im Wissen darum, nicht jünger zu werden, hoffte er nach wie vor, eine Weggefährtin zu finden, die die Liebe zu den Bergen mit ihm teilte und die Libido noch dazu.

Levi nahm sein Buch zur Hand, das ihm in den einsamsten Augenblicken seines Lebens immer mit Rat und Tat zur Seite stand: die Ars

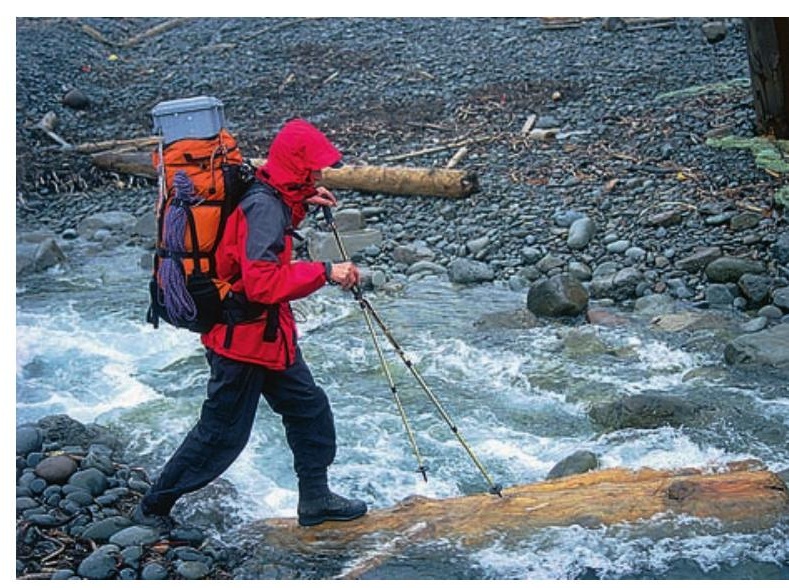

amandi. Und es wurde ihm schmählich bewusst, dass er kaum noch einmal Vater werden würde und er lediglich Beziehungen zu Antinori, dem Winzer, jedoch kaum zum Professore pflegte. Nur letzterer konnte die Gesetze der Natur, wonach, wer seine biologische Schuldigkeit getan hatte, von der Natur ausgemustert wurde, aushebeln, wenn auch nur mit üblen Tricks.

Levi Tramonte warf die Ars amandi auf die Via Gracialis und staunte nicht schlecht, als sich vor ihm ein Riesenpuff auftat. Rasch lief er auf die Strasse runter, doch dabei rutschte er aus, brach sich das Schambein und den Schenkelhals und schrie nach Hilfe. Die Droschke fuhr vor, man hob ihn auf einen Tisch, einen mit Whisky getränkten Lappen schoben sie zwischen oberes und unteres Implantat. Unter Höllengeschrei begann einer mit Maske zu sägen, und Levi Tramonte wünschte im Erdboden zu versinken. Als er aufwachte, lagen die Ars amandi und seine Lebensgefährtin neben ihm. Ein zarter Kuss auf die Wange holte ihn ins Diesseits zurück. 